\title{
A mixed methods study to compare models of spirometry delivery in primary care for patients at risk of COPD
}

\author{
J A Walters, E C Hansen, D P Johns, E L Blizzard, E H Walters, R Wood-Baker
}

\section{See Editorial, p 387}

Menzies Research Institute, University of Tasmania, Australia

Correspondence to: Dr J A Walters, Menzies Research Institute, PB 34 Clinical School, University of Tasmania, Hobart 7001 Australia; Julia.Walters@ utas.edu.au

Received 17 April 2007 Accepted 1 November 2007 Published Online First 5 December 2007
ABSTRACT

Background: To increase recognition of airflow obstruction in primary care, we compared two models of spirometry delivery in a target group at risk of chronic obstructive pulmonary disease (COPD).

Methods: A 6 month qualitative/quantitative cluster randomised study in eight practices compared opportunistic spirometry by "visiting trained nurses" (TN) with optimised "usual care" (UC) from general practitioners (GPs) for smokers and ex-smokers, aged over 35 years. Outcomes were: spirometry uptake and quality, new diagnoses of COPD and GPs' experiences of spirometry. Results: In the eligible target population, 531/904 (59\%) patients underwent spirometry in the TN model and 87/ 1130 (8\%) patients in the UC model $(p<0.0001)$. ATS spirometry standards for acceptability and reproducibility were met by $76 \%$ and $44 \%$ of tests in the TN and UC models, respectively $(p<0.0001) .125(24 \%)$ patients tested with the TN model and 38 (44\%) with the UC model reported a pre-existing respiratory diagnosis $(p<0.0001)$. Three months after spirometry, when the ratio of forced expiratory volume in $1 \mathrm{~s} /$ forced vital capacity $\left(\mathrm{FEV}_{1} / \mathrm{FVC}\right)$ was $<0.7$ and no prior COPD diagnosis was reported, nine (8\%) participants had a new doctor recorded COPD diagnosis in practices with the TN model and two (8\%) participants in practices with the UC model. Mislabelling of participants with a diagnosis of COPD when $\mathrm{FEV}_{1} / \mathrm{FVC}$ was $\geqslant 0.7$ was present in both models prior to and after spirometry. GPs valued high quality spirometry and increased testing of patients at risk of COPD in the TN model. They identified limitations, including the need for better systematic follow-up of abnormal spirometry and support with interpretation, which may explain persisting underdiagnosis of COPD in practice records.

Conclusions: Although opportunistic testing by visiting trained nurses substantially increased and improved spirometry performance compared with usual care, translating increased detection of airflow obstruction into diagnosis of COPD requires further development of the model.

Trial registration number: Australian Clinical Trials Registry: registration No 12605000019606.

A high proportion of chronic obstructive pulmonary disease (COPD) in the community remains undiagnosed. ${ }^{12}$ Previously unrecognised airflow obstruction was found in 19\% of current smokers over 35 years of age in general practice ${ }^{3}$ and although spirometry is essential for the diagnosis of COPD,${ }^{45}$ performing spirometry in primary care is not without difficulties. These include lack of access to reliable equipment, lack of training, patient reluctance to travel and financial disincentives. $^{6-8}$ There has been little operational research on how to overcome such practical difficulties. The aim of this study was to compare the effects of two practice based models of spirometry delivery, opportunistic spirometry by visiting trained nurses and "usual care" in practices provided with equipment, training and payment, on spirometry uptake and application in patients at risk of COPD and translation into new diagnoses of COPD recorded by general practitioners (GPs).

\section{METHODS}

\section{Participants and study design}

Practices were recruited through a newsletter distributed to all practices in Southern Tasmania (74 urban/suburban and 20 rural). Six urban and two rural general practices responded and were included and randomised. The study protocol was approved by the Southern Health and Medical Human Research Ethics Committee. Signed informed consent was obtained from GPs in participating practices and from patients at recruitment, which occurred between November 2004 and June 2005.

\section{Spirometry delivery models}

Using a random numbers table, practices were randomised to models for delivery of spirometry to patients in the target group at risk of COPD defined by: age over 35 years and ever smoked regularly. In the trained nurse model (TN), nurses trained in spirometry testing visited each practice for two $3 \mathrm{~h}$ sessions per week to perform opportunistic testing. Practice staff invited any patient in the target group who attended during a spirometry session to undergo lung function testing Spirometry was also advertised by posters or performed at the request of GPs. Printed spirometer output (without classification or interpretation) was faxed to GPs within $48 \mathrm{~h}$

In the usual care model (UC) model, a spirometer was provided to the practice and education and spirometry training given. After training, spirometry was performed by a GP or practice nurse/assistant according to the usual practice protocol. Practice publicity was discretionary (eg, computer generated reminders or posters). Practices retained spirometry traces for GP interpretation and received reimbursement for patients tested in the target group (AUS\$10, proportionate to an existing Australian Medicare schedule fee for spirometry with reversibility testing) 


\section{Spirometry training}

In practices receiving either intervention, GPs and other nominated staff were trained during a $2 \mathrm{~h}$ workshop (see appendix 1) by a physiologist and respiratory specialist physician in performance of spirometry (theory and practice), interpretation and criteria for diagnosing COPD according to Global Initiative for Chronic Obstructive Lung Disease (GOLD) ${ }^{4}$ and Australian ${ }^{5}$ guidelines (forced expiratory volume in $1 \mathrm{~s} /$ forced vital capacity $\left.\left(\mathrm{FEV}_{1} / \mathrm{FVC}\right)<0.7\right)$.

\section{Outcome data collection}

\section{Spirometry uptake and acceptability}

Demographic data were collected for all patients offered spirometry. Additionally, reasons for accepting or refusing spirometry were recorded for patients offered an opportunistic test. Participants undergoing spirometry completed questionnaires recording smoking history, assessment of functional breathlessness using the Medical Research Council (MRC) dyspnoea scale ${ }^{9}$ and self-reported use of respiratory medications and diagnoses.

\section{Spirometry}

Spirometry was performed in all practices using an ultrasonic electronic spirometer (EasyOne, NDD Medizintechnik AG, Technoparkstrasse, Switzerland). This spirometer has the advantage of stability, ${ }^{10}$ inbuilt quality assurance features, ${ }^{11}$ classifies tests using grades (A-D, F) for reliability (see appendix 2) and provides prompts to optimise performance. Investigators performed regular calibration checks. A spirometry test consisted of three expiratory manoeuvres (emphasising full inspiration and complete exhalation) meeting American Thoracic Society (ATS) acceptability and repeatability criteria, performed without bronchodilator reversibility testing. ${ }^{11}$ The time to complete testing was recorded in the TN model. Predicted values were calculated from Knudson and colleagues. ${ }^{12}$ Reports provided to GPs included the parameters $\mathrm{FEV}_{1}, \mathrm{FVC}$, $\mathrm{FEV}_{1} / \mathrm{FVC}$ ratio, forced expiratory flow $(\mathrm{FEF})_{25-75 \% \text {, peak }}$ expiratory flow and forced expiratory time for three acceptable manoeuvres with corresponding flow-volume and volume-time curves.

\section{Quality assurance}

Spirometry was assessed by investigators against contemporary ATS criteria ${ }^{11}$ for acceptability and repeatability (see appendix 2 ). The proportions of acceptable spirometry that showed a difference between the best two $\mathrm{FEV}_{1}$ and best two FVC $\leqslant 200 \mathrm{ml}$ (grade A or B) were compared between models. The utility of spirometry for interpretation by GPs was evaluated by assessing the proportion of spirometry of poor quality grades (D, two acceptable but not repeatable tests; F, only one acceptable test or no acceptable test achieved).

Impact of spirometry on diagnosis of COPD

A definition of the presence of airflow obstruction $(\mathrm{AO})$ based on the principal criterion $\left(\mathrm{FEV}_{1} / \mathrm{FVC}<0.7\right)$ specified in (GOLD) guidelines ${ }^{4}$ was used for investigator assessment of a doctor diagnosis of COPD following spirometry. ${ }^{13}$ When spirometry met any of the following criteria, practice records of patients belonging to the target group were examined by investigators 3 months later: $\mathrm{FEV}_{1} / \mathrm{FVC}<85 \%$ predicted, $\mathrm{FEV}_{1}<80 \%$ predicted, FVC $<80 \%$ predicted or $\mathrm{FEF}_{25-75 \%}<55 \%$ predicted. Data were extracted on further investigations by GPs, including post-bronchodilator spirometry, and doctor recorded diagnoses of respiratory disease before and after spirometry.

\section{Qualitative assessment of spirometry delivery models}

At the conclusion of the study, focus group discussions were conducted with GPs in each practice. A trained facilitator used both general and specific questions relevant to each spirometry model with case scenarios to generate discussion. ${ }^{14}$

\section{Statistical analysis}

Two trained nurses were expected to recruit a maximum of 30 patients per week for opportunistic spirometry. No data on the rate of spirometry refusal in the target group were available. Assuming a $25 \%$ refusal rate, we anticipated testing a maximum
Figure 1 Study flow chart. FTE, full time equivalent; GP, general practitioner; PN, practice nurse. Target group: age $\geqslant 35$ years, smoker or ex-smoker.

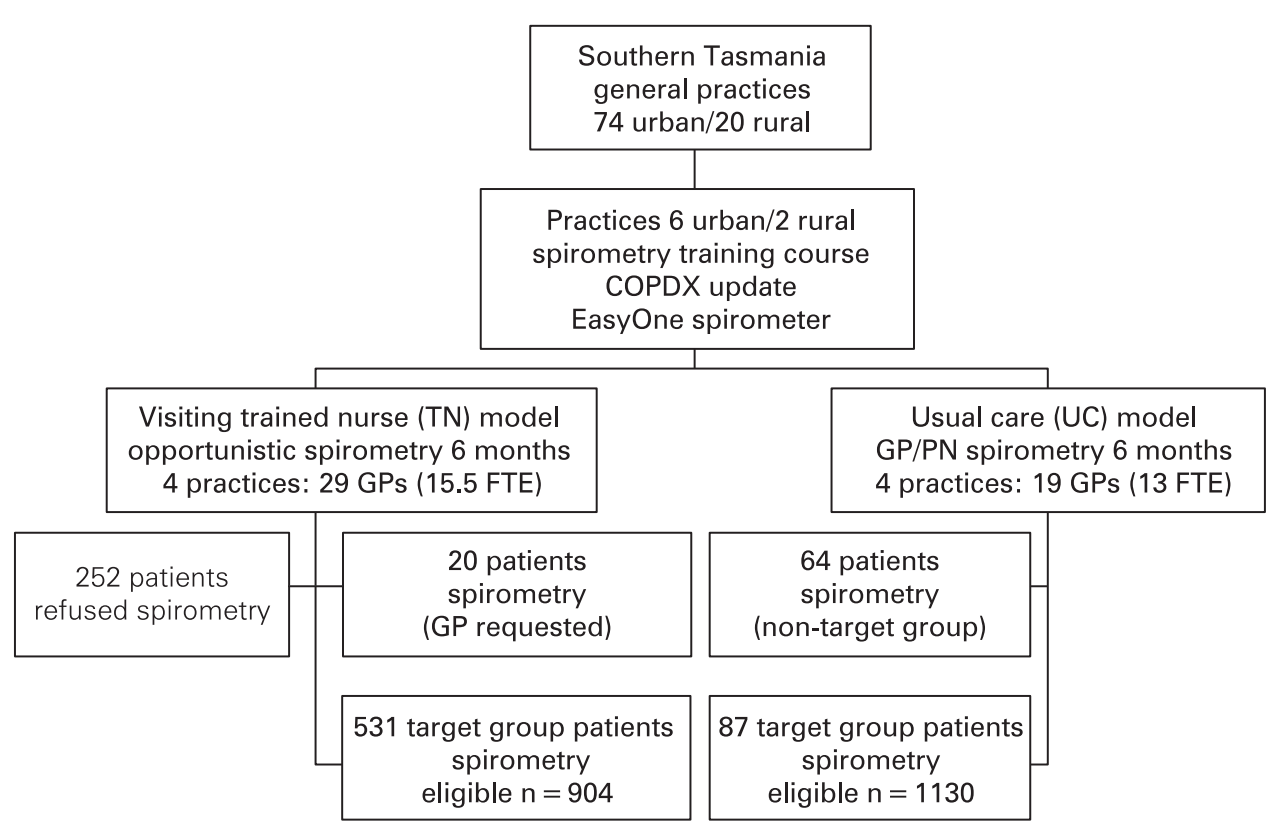


Table 1 Characteristics of patients belonging to the target group (age $\geqslant 35$ years, ever smoker) undergoing spirometry in practices by spirometry delivery model

\begin{tabular}{lclc}
\hline & $\begin{array}{l}\text { Visiting trained } \\
\text { nurse spirometry } \\
\text { (n = 531) }\end{array}$ & $\begin{array}{l}\text { Usual care } \\
\text { spirometry } \\
(\mathbf{n}=\mathbf{8 7})\end{array}$ & p Value \\
\hline Males (\%) & $258(48.6)$ & $41(47.1)$ & 0.78 \\
Current smokers (\%) & $204(38.4)$ & $32(37.6)$ & 0.69 \\
Age (y)* & $56.0(21.0)$ & $57.4(21.0)$ & 0.94 \\
Smoking history (pack years) & $26.3(27.4)$ & $35.6(31.4)$ & 0.15 \\
MRC functional dyspnoea $\geqslant 3(\%)$ & $127(23.9)$ & $35(40.2)$ & $<0.0001$ \\
Self-report respiratory diagnosis $\dagger(\%)$ & $125(23.5)$ & $38(43.7)$ & $<0.0001$ \\
Self-report diagnosis of COPD (\%) & $33(6.2)$ & $11(12.8)$ & 0.04 \\
FEV ${ }_{1} \%$ predicted $\dagger$ & $95.0(26.0)$ & $86.5(34.0)$ & 0.07 \\
\hline
\end{tabular}

Data are presented as ${ }^{*}$ median and IOR.

$\dagger$ Asthma, chronic obstructive pulmonary disease, chronic bronchitis or other participant specified diagnosis.

FEV 1 , forced expiratory volume in $1 \mathrm{~s}$; MRC, Medical Research Council.

of 1170 participants in four TN practices. Based on a previous study, ${ }^{7}$ the expected rate of spirometry was 2.3 tests per week, 240 tests in UC practices. Planned comparisons were the number of tests performed in 6 months and proportions of the eligible target group tested in practices. The eligible population in the TN model consisted of patients in the target group who attended for any reason during spirometry sessions over 6 months, calculated as the number invited plus those who missed an invitation to participate. The eligible population in the UC model consisted of all patients in the target group who consulted a GP at least once during the study. This was calculated from consultation numbers during 6 months minus: numbers of lifelong non-smokers and under 35 year of age, allowing for the proportion of patients making repeat attendances estimated from attendance data extracted from practice records. Quantitative data analyses were performed using SPSS V.14.0 and STATA V.10. Variables are presented as means (SD) or median (interquartile range (IOR)) if non-normally distributed. Clustering was taken into account in regression analyses with random intercepts using multi-level mixed effects linear models or generalised linear latent and mixed models. Comparison of proportions tested in practices was performed using a $t$ test weighted by the number of eligible patients. ${ }^{15}$ Statistical significance was set at the $5 \%$ level.

Qualitative data were analysed using NVivo (V.2, Qualitative Solutions and Research International, Melbourne, Victoria, Australia). Focus group discussions were audiotaped and transcribed verbatim. An iterative process of inductive category development was used for content analysis. ${ }^{14}$ Two researchers (JW, JG or EH) listened to all tapes to identify the initial themes. JW analysed transcripts line-by-line, coded relevant themes and categories, and recorded thematic development using memos. Emergent themes were verified by $\mathrm{EH}$ and discussed among all authors. Themes and sub-themes were compared by spirometry delivery models. Examples of quotes were used to illustrate themes.

\section{RESULTS}

\section{Spirometry uptake, application and feasibility}

Opportunistic spirometry was performed on 531 participants in the target group of patients in the TN model while 87 participants in the target group were tested by GPs or practice nurses in the UC model over a period of 6 months. There was a significant difference between proportions of the estimated eligible target group population that underwent spirometry in practices in the TN model and in practices with the UC model $(p<0.0001)$, overall 58.7 versus $7.7 \%$ (fig 1 ).

Patients tested in the target group in both delivery models had similar profiles for age, gender, current smoker status and smoking pack-year history (table 1). In the TN model, a lower proportion of patients tested opportunistically reported a preexisting respiratory diagnosis and a lower proportion had functional dyspnoea of MRC grade 3 or 4 compared with those tested in the UC model (table 1). Airflow obstruction ( $\mathrm{FEV}_{1} /$ FVC <0.7) was present in $127(23.9 \%)$ patients tested in the TN model and in 29 (33.3\%) patients tested in the UC spirometry delivery model $(p=0.06)$. When participants reported no prior diagnosis of COPD, the severity of airflow obstruction classified using $\mathrm{GOLD}^{4}$ in the TN model compared with the UC model was: mild in $48(44.9 \%)$ versus seven $(27.4 \%)$, moderate in 48 $(44.9 \%)$ versus $12(48.0 \%)$, severe in $10(9.3 \%)$ versus three $(12.0 \%)$ and very severe in one $(1 \%)$ versus three $(12.0 \%)$ $(p=0.03)$.

An invitation to undergo spirometry testing in the TN model was offered to 783 patients and refused by 252 patients (32\%) (fig 1). Patient specified reasons for refusing were generally either "feeling too unwell" or "lack of time on this visit to the GP" (table 2). Only a minority were "not interested in knowing their lung function" or refused because they "thought their lungs were OK". Among patients who accepted, the most frequent reason was "I'd like to know my lung function". Median time taken for opportunistic spirometry testing in the TN model was $5 \mathrm{~min}$ (IOR 2) and the median number of attempts required to complete acceptable spirometry was 4 (IOR 2).

\section{Spirometry quality}

Spirometry grading was A or B in $421 / 551$ (76.4\%) tests in the TN model compared with 66/151 (43.7\%) tests performed in the UC model by GPs and practice nurses $(\mathrm{p}<0.0001)$. Grading was C for $78(14.2 \%)$ and $29(19.2 \%)$ and D or F in $52(9.5 \%)$ and 56 $(37.0 \%)$ in $551 \mathrm{TN}$ tests and $151 \mathrm{UC}$ tests, respectively $(\mathrm{p}<0.0001)$.

Table 2 Patients' reasons* for accepting or declining spirometry in practices with the trained nurse model of spirometry delivery

\begin{tabular}{llll}
\hline Spirometry performed $(\mathbf{n = 5 3 1 )}(\%)$ & \multicolumn{1}{l}{ Refused spirometry $(\mathbf{n}=\mathbf{2 5 2})(\%)$} \\
\hline Like to know lung function & $341(65.1)$ & Not interested in knowing & $64(25.5)$ \\
Check up & $315(60.6)$ & Think lungs are OK & $52(20.7)$ \\
Worried about my lungs & $123(23.4)$ & Result might worry me & $17(6.8)$ \\
Saw a poster & $95(18.7)$ & Do not like having tests & $13(5.2)$ \\
Other-patient specified & $68(13.0)$ & Other-patient specified & $176(70.7)$ \\
\hline
\end{tabular}

*Multiple responses permitted. 
Figure 2 Impact of spirometry on the diagnosis of chronic obstructive pulmonary disease (COPD) in practices receiving the visiting trained nurse (TN) or usual care (UC) model of spirometry delivery. AO, spirometry demonstrated airflow obstruction forced expiratory

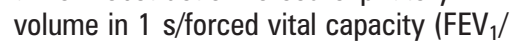
FVC) $<0.7$. Target group: age $\geqslant 35$ years, smoker or ex-smoker.

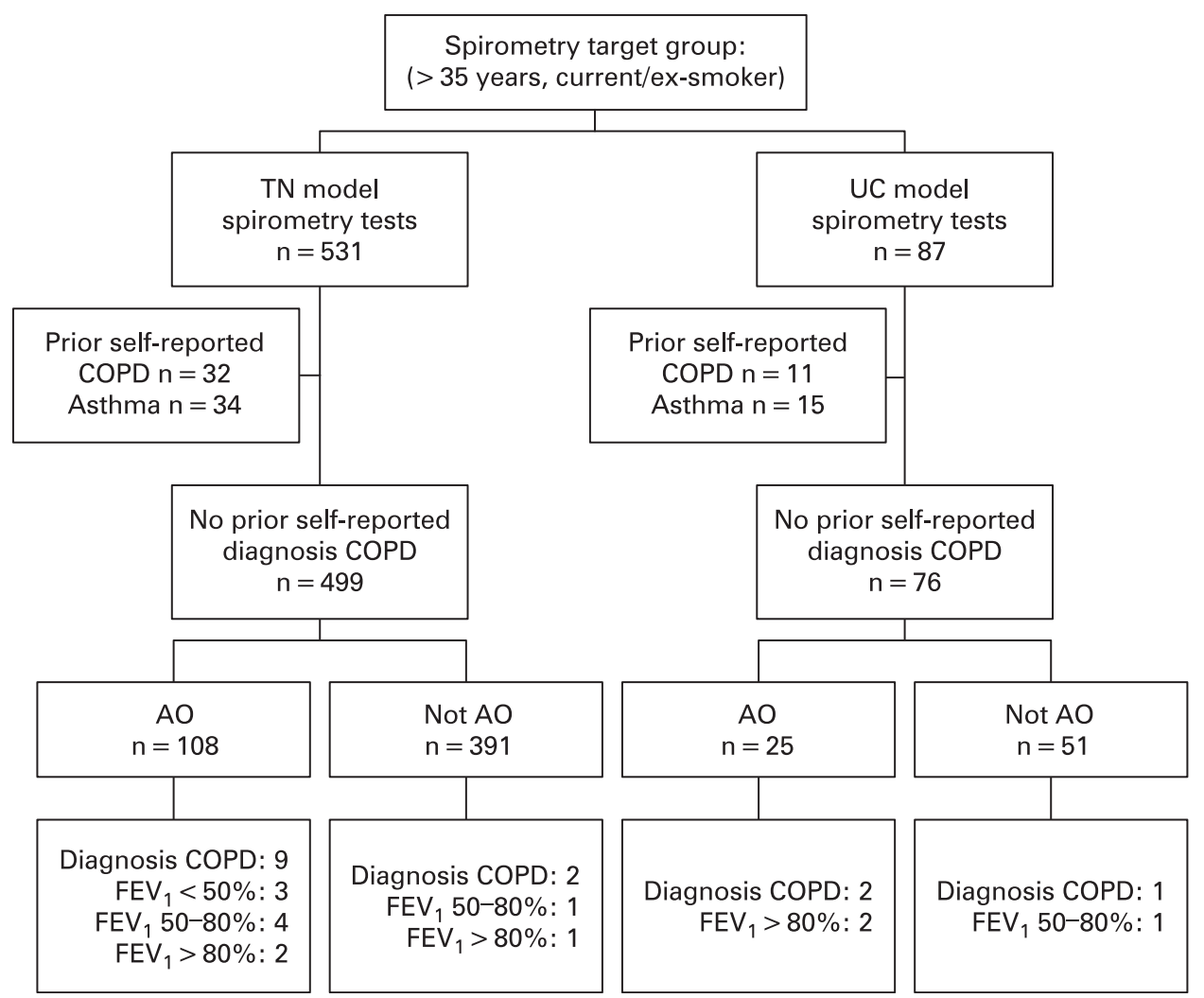

Table 3 Summary of themes on spirometry from focus group discussions with general practitioners in practices receiving the visiting trained nurse (TN) model or usual care (UC) model of spirometry delivery

\begin{tabular}{|c|c|c|c|}
\hline Spirometry theme & TN & UC & Typical examples of statements by a GP \\
\hline High quality essential & Yes & Yes & $\begin{array}{l}\text { "It seems quite critical, that the person doing the actual testing is } \\
\text { trained, and is aware of patients' technique" TN model }\end{array}$ \\
\hline $\begin{array}{l}\text { GPs lack time to perform good quality } \\
\text { spirometry }\end{array}$ & No & Yes & "You'd have to use it all the time to get really efficient" UC model \\
\hline Initiation by GPs not required & Yes & No & $\begin{array}{l}\text { "I probably wouldn't be requesting spirometry, unless I already } \\
\text { knew there was a problem" TN model }\end{array}$ \\
\hline $\begin{array}{l}\text { Nurse performed spirometry is less } \\
\text { threatening for patients }\end{array}$ & Yes & Yes & $\begin{array}{l}\text { Nurses are "not too authoritarian" and are "very non-threatening" } \\
\text { TN model }\end{array}$ \\
\hline Systematic follow-up not achieved & Yes & No & $\begin{array}{l}\text { "It is fitted in among whatever is of primary concern to them, and } \\
\text { so tends to go to the bottom of the heap" TN model }\end{array}$ \\
\hline Lack of ownership of test result & Yes & No & $\begin{array}{l}\text { "If I order a test I have some obligation to follow-up the results and } \\
\text { discuss it with the patient" TN model }\end{array}$ \\
\hline Use in differential diagnosis & Yes & Yes & "I am looking for a reason why they are short of breath" UC model \\
\hline $\begin{array}{l}\text { Emphasis on clinical basis for diagnosis of } \\
\text { respiratory disease }\end{array}$ & Yes & Yes & $\begin{array}{l}\text { "You can support what you already know, she is developing a } \\
\text { respiratory problem with her smoking" TN model }\end{array}$ \\
\hline Usefulness of recording a diagnosis of COPD & Yes & Yes & $\begin{array}{l}\text { "If you give them a label or not, I think it depends on what } \\
\text { impression you give of how serious it actually seems to be, rather } \\
\text { than just a label." TN model }\end{array}$ \\
\hline Classifying the severity of COPD & Yes & Yes & $\begin{array}{l}\text { "Well it helps you in making a diagnosis and helps you to quantify } \\
\text { the degree of damage" TN model }\end{array}$ \\
\hline Objective measurement useful in future & Yes & No & $\begin{array}{l}\text { "Same as with hypertension, you have got a baseline of respiratory } \\
\text { function" TN model }\end{array}$ \\
\hline \multirow[t]{2}{*}{ Identifying and recording smoking status } & \multirow[t]{2}{*}{ Yes } & \multirow[t]{2}{*}{ Yes } & $\begin{array}{l}\text { "I have identified a few patients who I didn't know were smokers. I } \\
\text { always thought I could smell them" UC model }\end{array}$ \\
\hline & & & $\begin{array}{l}\text { "I have been unaware they are smokers, or even ex-smokers" TN } \\
\text { model }\end{array}$ \\
\hline Discussing smoking cessation & Yes & Yes & "It is an entry into talking about how to give up" TN model \\
\hline Personalise quit advice & Yes & Yes & $\begin{array}{l}\text { "You could say that if she stopped smoking there is a good chance } \\
\text { she won't get any worse" UC model }\end{array}$ \\
\hline $\begin{array}{l}\text { Cost a disincentive without appropriate } \\
\text { funding }\end{array}$ & Yes & Yes & $\begin{array}{l}\text { "Unless you are doing full lung function, you can't claim anything" } \\
\text { UC model }\end{array}$ \\
\hline
\end{tabular}




\section{Impact of spirometry on diagnosis of COPD}

\section{Examination of practice records}

A total of 277 (52\%) tests conducted in the TN model and 39 $(45 \%)$ tests conducted in the UC model did not meet the prespecified spirometric criteria for proceeding to practice record data extraction. In patients whose spirometry met the criteria, data extraction was successfully completed for $266(89 \%)$ patients in practices with the TN model and in 40 (83\%) patients in practices with the UC model. Records for 37 patients were unavailable to investigators.

In practices with the TN spirometry model, 190 (84\%) patients had consulted a GP by 3 months after spirometry and in these patients there were 11 new doctor recorded diagnoses of COPD, $2.2 \%$ of participants without prior self-reported COPD (fig 2). When spirometry demonstrated airflow obstruction $\left(\mathrm{FEV}_{1} / \mathrm{FVC}<0.7\right)$, there were nine new doctor recorded diagnoses of COPD, an $8.3 \%$ increase by 3 months following spirometry. Two patients with an $\mathrm{FEV}_{1} / \mathrm{FVC}$ ratio $\geqslant 0.7$ had a new doctor recorded COPD diagnosis. Among participants with a prior self-reported diagnosis of COPD, 19 (60\%) demonstrated airflow obstruction. In practices with the UC spirometry model, two (8\%) participants with airflow obstruction received a new doctor recorded diagnosis of COPD (fig 2). Among those with a prior self-reported COPD diagnosis, four (36\%) demonstrated airflow obstruction.

\section{Cost of spirometry in TN model}

The cost of opportunistic spirometry in the TN model over 6 months was AUS\$42 704 (\$804 for spirometry training courses, $\$ 33800$ for nurse costs, $\$ 6500$ for spirometers, $\$ 1600$ for spirettes). The cost per new case of doctor recorded obstructive airways disease where spirometry in the target group showed airflow obstruction $\left(\mathrm{FEV}_{1} / \mathrm{FVC}<0.7\right)$ would be AUS $\$ 555$ if all cases received a diagnosis. However, for the 12 new doctor recorded diagnoses of COPD or asthma, the cost was AUS\$3559 per case (€2246).

\section{GP experience}

Fifteen GPs (52\%) from practices with the TN model and 13 GPs $(68 \%)$ from practices with the UC spirometry model participated in six in-depth focus groups. Of the major themes that emerged (table 3), some were important for GPs from practices with either spirometry model, such as the need for appropriate spirometry reimbursement and the necessity of achieving high quality results. Only in practices with the UC model did GPs emphasise their own difficulties in performing spirometry and the paramount importance of having a practice nurse to perform spirometry testing. GPs in practices with the TN model thought GP initiated spirometry would be unlikely in the absence of a prior diagnosis and felt that opportunistic spirometry had major advantages for convenience and acceptability to patients. This was particularly relevant for smokers who might be reluctant to raise concerns about respiratory symptoms with GPs, because they felt guilty about self-induced lung damage. Organised follow-up, specifically focussed on spirometry, was thought essential in both models of spirometry, but a recall system after opportunistic testing would increase an already heavy GP workload and increase costs for patients in Australian primary care.

All GPs claimed to use spirometry to diagnose COPD but rarely in isolation, often placing greater emphasis on other clinical patient information. They questioned the value of the label, both in terms of patient understanding and promoting change in patient behaviour. A label was felt by some GPs to lack intrinsic value in the absence of a cure. When considering the scenario of a patient with spirometry typical of moderate COPD, various terms used as labels included "reduced lung function", "obstructive" and "respiratory problem", and COPD was rarely specifically named. GPs varied in their knowledge of spirometric indices, but most expressed uncertainty and agreed they needed assistance with interpretation. Options suggested were: developing expertise within a practice, computerised support or outside expert interpretation. Flow-volume curves were valued by GPs themselves in assessing the presence of obstruction and in demonstrating this to patients. Only GPs in practices with the TN model valued spirometry for monitoring lung function objectively and compared this positively to routine management of other chronic diseases such as diabetes and hypertension.

The most likely consequences of spirometry elicited from GPs in both spirometry models were being prompted to identify and record patients' smoking status and initiate discussion on cessation. Spirometry, even when normal, was used to personalise and reinforce advice on quitting.

\section{DISCUSSION}

This study was unique in using qualitative assessment to explore and validate quantitative findings ${ }^{16}{ }^{17}$ of the impact of two models of delivery of spirometry in general practice. ${ }^{18} \mathrm{We}$ found that opportunistic trained nurse performed spirometry led to a substantially higher proportion of the population at risk of developing COPD having spirometry performed compared with usual care by GPs equipped and trained in spirometry. Spirometry performed in both models resulted in an increase in GP diagnosis of COPD. However, in practices with the visiting TN model, substantial underdiagnosis remained after a period that allowed for follow-up and further investigations in patients with spirometric evidence of airflow obstruction.

Direct invitations for spirometry by a nurse were highly acceptable to patients and GPs, although we had a higher nonparticipation rate compared with other similar studies, ${ }^{3}{ }^{19}$ mainly caused by time constraints and illness in this opportunistic testing model within the GP clinic. However, the study design aimed to reflect busy "real world" general practice, both without pre-selection or exclusions in the target group and in utilisation and interpretation of spirometry by GPs.

The high proportion of visiting nurse performed spirometry satisfying ATS standards for acceptability and repeatability ${ }^{11}$ was similar to that reported in studies using trained staff in general practice ${ }^{30}$ or in the community ${ }^{21}$ and greater than achieved in practices with the UC model where the quality was variable and reflected the lack of GP expertise self-identified in our qualitative data. There was a consensus that the nature of GPs' work was not compatible with performing spirometry to consistently high standards, but this could be achieved with adequate training and experience by practice nurses. A low rate of good quality testing in practice was found previously ${ }^{7}$ although a recent study found higher rates achieved in some practices with intensive 2 day spirometry training. ${ }^{22}$

Use of spirometry without post-bronchodilator measurement in order to limit refusals ${ }^{23}$ may overestimate the prevalence of airflow obstruction in each model. However, more mild obstruction was identified by opportunistic testing compared with testing in the UC model or as reported in an open access spirometry service for GPs in the UK. ${ }^{21}$ Spirometry use for a diagnosis of COPD is low with models that rely on GP initiation or referral. ${ }^{24}{ }^{25}$ Our qualitative data indicated that initiation of 
testing may not occur in the absence of previously identified disease with known underreporting by patients of symptoms. ${ }^{26}$

This study investigated the utility of different spirometry models to increase the diagnosis of COPD in actual primary care practice. The high level of missed opportunities for new diagnosis in patients with airflow obstruction and mislabelling of COPD found in practice record review are consistent with findings in other studies in primary care. ${ }^{73} 27$ Methods suggested by GPs to improve interpretation seem feasible and deserve further investigation. ${ }^{28}$ In addition to failure to interpret spirometry correctly, qualitative data analysis identified other factors contributing to non-diagnosis, including non-consultation by patients, time limitations and GPs' preference for reactively addressing the patient's own agenda during a consultation rather than being proactive. These factors have also been found to be deterrents to GPs initiating discussions with smokers. ${ }^{29}$

Cost effectiveness of spirometry for case finding in COPD will vary if a symptom screening tool is used ${ }^{30}$ but depends on subsequent reduced costs through better management and reduced progression of the disease resulting from successful smoking cessation. ${ }^{31}$ While we found GPs valued opportunistic testing primarily to improve identification of smoking status and initiate discussion on cessation, there is still no definitive conclusion on a positive impact of spirometry on smoking cessation. ${ }^{32}$

Consideration of the value of spirometry in primary care and choice of the most effective model for delivery requires a full cost-benefit analysis. Although data on costs have been generally lacking for other models they are included here to facilitate comparison. ${ }^{13}{ }^{21}$ A cost-benefit analysis using data on opportunistic testing in patients at risk of $\mathrm{COPD}^{3}$ carried out for the National Institute of Clinical Excellence ${ }^{33}$ found spirometry was relatively cost effective in case finding (assuming optimum interpretation) compared with current practice in primary care. Incomplete follow-up of airflow obstruction detected on spirometry caused a large increase in cost per case in our study.

Our analysis assumes participating practices were a random sample of those in Southern Tasmania but although they contained a representative range, we cannot discount selection bias and the findings may not be generalisable to all primary care practice. UC model practices had involvement in medical training and willingness to participate in research. They may be more knowledgeable about guidelines and perform more spirometry than others. ${ }^{34}$

We conclude that it is possible to increase spirometry for case finding in primary care using a model of testing by visiting trained nurses. However, to translate increased detection of airflow obstruction into increased COPD diagnosis requires measures to overcome issues identified by qualitative analysis and, at the very least, provide GPs with assistance in interpretation of spirometry. ${ }^{18}$

Acknowledgements: The authors thank Professor P Mudge for comment on study design, and the doctors and staff in participating practices for their cooperation. The authors thank research nurses S Davoren and E Hammer for performing spirometry and calibration checks, Dr J Gartlan and Dr R Boland who assisted with extraction of data from practice records.

Funding: JAW was the recipient of a 2006 GlaxoSmithKline Australia postgraduate support grant.

\section{Competing interests: None.}

Ethics approval: The study protocol was approved by the Southern Health and Medical Human Research Ethics Committee.

\section{REFERENCES}

1. Mannino D, Gagnon R, Petty T, et al. Obstructive lung disease and low lung function in adults in the United States: data from the National Health and Nutrition Examination Survey, 1988-1994. Arch Intern Med 2000;160:1683-9.
2. Pena V, Miravitlles M, Gabriel R, et al. Geographic variations in prevalence and underdiagnosis of COPD: results of the IBERPOC multicentre epidemiological study. Chest 2000;118:981-9.

3. Van Schayck C, Loozen J, Wagena E, et al. Detecting patients at a high risk of developing chronic obstructive pulmonary disease in general practice: cross sectional case finding study. BMJ 2002;324:1370-5.

4. Pauwels RA, Buist AS, Calverley PM, et al. Global strategy for the diagnosis, management, and prevention of chronic obstructive pulmonary disease. NHLBI/WHO Global Initiative for Chronic Obstructive Lung Disease (GOLD) Workshop summary. Am J Respir Crit Care Med 2001;163:1256-76.

5. McKenzie DK, Frith PA, Burdon JG, et al. The COPDX Plan: Australian and New Zealand Guidelines for the management of Chronic Obstructive Pulmonary Disease 2003. Med J Aust 2003;178:S7-39.

6. Walters JA, Hansen E, Mudge $P$, et al. Barriers to the use of spirometry in general practice. Aust Fam Physician 2005;34:201-203.

7. Eaton $\mathbf{T}$, Withy $S$, Garrett JE, et al. Spirometry in primary care practice: The importance of quality assurance and the impact of spirometry workshops. Chest 1999;116:416-24.

8. Goeman DP, Hogan CD, Aroni RA, et al. Barriers to delivering asthma care: a qualitative study of general practitioners. Med J Aust 2005;183:457-60.

9. Fletcher C. Standardised questionnaire on respiratory symptoms: a statement prepared and approved by the MRC committee on the aetiology of chronic bronchitis (MRC breathlessness score). BMJ 1960;2:1665.

10. Walters J, Wood-Baker R, Walls J, et al. Stability of the EasyOne ultrasonic spirometer for use in general practice. Respirology 2006;11:306-10.

11. American Thoracic Society. Standardization of Spirometry, 1994 Update. Am J Respir Crit Care Med 1995;152:1107-36.

12. Knudson RJ, Slatin R, Lebowitz M, et al. The maximal expiratory flow-volume curve. Am Rev Respir Dis 1976;113:587-600.

13. Dales RE, Vandemheen $\mathrm{KL}$, Clinch J, et al. Spirometry in the primary care setting: Influence on clinical diagnosis and management of airflow obstruction. Chest 2005:128:2443-7.

14. Grbich C. Qualitative Research in Health: an introduction. NSW, Australia: Allen and Unwin, 1999.

15. Kerry SM, Bland JM. Analysis of a trial randomised in clusters. BMJ 1998;316:54

16. Sandelowski M. Focus on qualitative methods: Using qualitative methods in intervention studies. Res Nurs Health 1996;19:359-64.

17. Morgan DL. Practical strategies for combining qualitative and quantitative methods: applications to health research. Qual Health Res 1998;8:362-76.

18. Poels PJ, Hartman TC, Schermer TR. Qualitative studies to explore barriers to spirometry use: a breath of fresh air? Respir Care 2006;51:768.

19. Seamark D, Williams S, Timon S, et al. Home or surgery based screening for chronic obstructive pulmonary disease (COPD). Prim Care Respir J 2001;10:30-3.

20. Schermer T, Jacobs J, Chavannes $N$, et al. Validity of spirometric testing in a general practice population of patients with chronic obstructive pulmonary disease (COPD). Thorax 2003;58:861-6.

21. Walker PP, Mitchell P, Diamantea F, et al. Effect of primary care spirometry on the diagnosis and management of COPD. Eur Respir J 2006;28:945-52.

22. Yawn BP, Enright PL, Lemanske RF Jr, et al. Spirometry can be done in family physicians' offices and alters clinical decisions in management of asthma and COPD. Chest 2007;132:1162-8.

23. van den Boom G, van Schayck CP, van Mollen MP, et al. Active detection of chronic obstructive pulmonary disease and asthma in the general population. Results and economic consequences of the DIMCA program. Am J Respir Crit Care Med 1998;158:1730-8.

24. Lee TA, Bartle B, Weiss KB. Spirometry use in clinical practice following diagnosis of COPD. Chest 2006;129:1509-15.

25. Poels PJP, Schermer TR, Jacobs A, et al. Variation in spirometry utilization between trained general practitioners in practices equipped with a spirometer. Scand J Prim Health Care 2006;24:81-7.

26. van den Boom G, Rutten-van Molken M, Tirimanna $P$, et al. Association between health-related quality of life and consultation for respiratory symptoms: results from the DIMCA programme. Eur Respir J 1998;11:67-72.

27. Chavannes N, Schermer T, Akkermans R, et al. Impact of spirometry on GPs diagnostic differentiation and decision-making. Respir Med 2004;98:1124-30.

28. Poels PJP, Schermer TRJ, van Weel C, et al. Spirometry in chronic obstructive pulmonary disease. BMJ 2006;333:870-1.

29. Coleman T, Murphy E, Cheater F. Factors influencing discussion of smoking between general practitioners and patients who smoke: a qualitative study. $\mathrm{Br} \mathrm{J}$ Gen Pract 2000;50:207-10

30. Price D, Tinkelman D, Nordyke R, et al. Scoring system and clinical application of COPD diagnostic questionnaires. Chest 2006;129:1531-9.

31. Wouters EF. Economic analysis of the confronting COPD survey: an overview of results. Respir Med 2003;97:S3-14.

32. Wilt T, Niewoehner D, Kim C-B, et al. Use of spirometry for case finding, diagnosis, and management of chronic obstructive pulmonary disease (COPD). Rockville, MD: Agency for Healthcare Research and Quality, 2005: Publication No. 05-E017-2.

33. National Institute for Clinical Excellence. Appendix B: The cost effectiveness of opportunistic case finding in primary care. Thorax 2004;59:175-90.

34. Tumiel-Berhalter LM, Watkins R. The impact of provider knowledge and attitudes toward national asthma guidelines on self-reported implementation of guidelines. J Asthma 2006:43:625-8. 


\section{Appendix 1}

Spirometry Training Course: for general practitioners and practice nurses

Instructors: respiratory specialist physician, pulmonary physiologist, GP.

Course content

- Spirometry performance (40 min)

- Demonstration of simple spirometry spirogram and complex spirometry flow volume loop

- Potential complications of spirometry

- Contraindications to spirometry:

- Requirements for achieving consistently high quality spirometry

- Test performance instructions

- Acceptance criteria (need to obtain at least 3 technically acceptable blows)

- Reproducibility criteria

- Common causes of poor quality spirometry

- How to get quality spirometry

- Trouble shooting: patient related (with examples of curves)

- Interpretation: types of ventilatory defects

- Use of predicted values

- Demonstration using Easy0ne spirometer and software $(20 \mathrm{~min})$

- Practice spirometry with EasyOne (30 min)

- Spirometry: application in COPD (30 min)

- Diagnosis of COPD, differentiation from asthma

- Interpretation of airflow obstruction and classification of severity
- COPDX guidelines - indications for spirometry

- Review of clinical case examples.

\section{Appendix 2 \\ Acceptability assessment}

1. Spirometry test did not meet EasyOne spirometer criteria for an unacceptable test:

a. back extrapolated volume greater than $150 \mathrm{ml}$ or $5 \%$ whichever is greater;

b. time until peak flow greater than $120 \mathrm{~ms}$;

c. expiration time less than $2 \mathrm{~s}$ or volume accumulation has not dropped below $100 \mathrm{ml}$ per $0.5 \mathrm{~s}$

2. exhalation time (forced expiratory time) less than $6 \mathrm{~s}$.

\section{Quality grading definitions used in Easy0ne spirometer:}

a. at least three acceptable tests AND the difference between the best two FEV and FVC values is equal to or less than $150 \mathrm{ml}$;

b. at least three acceptable tests AND the difference between the best two FEV and FVC values is equal to or less than $200 \mathrm{ml}$;

c. at least two acceptable tests AND the difference between the best two FEV and FVC values is equal to or less than $250 \mathrm{ml}$;

d. at least two acceptable trials but the results are not reproducible or only one acceptable trial;

e. no acceptable test available.

\section{Lung alert}

\section{No proof that lung transplantation improves survival in cystic fibrosis}

Lung transplantation is a common procedure with significant risks undertaken in children with cystic fibrosis. This retrospective study investigates the effect of lung transplantation on survival.

Five hundred and fourteen of 602 children $(85 \%)$ aged $<18$ years with cystic fibrosis placed on the lung transplantation waiting list in the USA between 1992 and 2002 were included in the study; 248 of these children subsequently underwent lung transplantation. Proportional hazards modelling identified Burkholderia cepacia infection, diabetes, increasing age and Staphylococcus aureus infection as factors other than transplantation that had an impact upon survival. By also modelling transplantation as a time-dependent covariate, the authors calculated that 5 patients had a significant estimated benefit, 315 had a significant risk of harm, 76 had an insignificant benefit and 118 had an insignificant risk of harm associated with lung transplantation.

Although other factors that could not be measured in the study may have affected survival, the data and methods used seem to justify the conclusion of the authors that lung transplantation should not be undertaken in children with cystic fibrosis with the aim of prolongation of life expectancy. They acknowledge, however, that it remains to be determined whether, for some children, lung transplantation can be justified on quality of life grounds against an acceptable complication and mortality risk. A prospective randomised trial will be required to determine whether this is indeed the case. Until such information is available, it is questionable under what circumstances lung transplantation should be performed in children with cystic fibrosis.

- Liou TG, Adler FR, Cox DR, et al. Lung transplantation and survival in children with cystic fibrosis. N Engl J Med 2007;357:2143-52

\section{lain Drummond}

Correspondence to: I Drummond, Specialist Trainee, Intensive Care, Queen Margaret Hospital, Dunfermline, UK; iaindrummond81@hotmail.com 